\title{
Penicillamine prevents ram sperm agglutination in media that support capacitation
}

\author{
T Leahy, J P Rickard, R J Aitken ${ }^{1}$ and S P de Graaf \\ Faculty of Veterinary Science, University of Sydney, Sydney, New South Wales 2006, Australia and ${ }^{1}$ Discipline of \\ Biological Sciences, Faculty of Science and IT and Faculty of Health and Medicine, University of Newcastle, \\ Callaghan, New South Wales 2308, Australia
}

Correspondence should be addressed to T Leahy; Email: tamara.leahy@sydney.edu.au

\begin{abstract}
Ram spermatozoa are difficult to capacitate in vitro. Here we describe a further complication, the unreported phenomenon of headto-head agglutination of ram spermatozoa following dilution in the capacitation medium Tyrodes plus albumin, lactate and pyruvate (TALP). Sperm agglutination is immediate, specific and persistent and is not associated with a loss of motility. Agglutination impedes in vitro sperm handling and analysis. So the objectives of this study were to investigate the cause of sperm agglutination and potential agents which may reduce agglutination. The percentage of non-agglutinated, motile spermatozoa increased when bicarbonate was omitted from complete TALP suggesting that bicarbonate ions stimulate the agglutination process. D-penicillamine (PEN), a nucleophilic thiol, was highly effective at reducing agglutination. The inclusion of $250 \mu \mathrm{M}$ PEN in TALP reduced the incidence of motile, agglutinated spermatozoa from $76.7 \pm 2.7 \%$ to $2.8 \pm 1.4 \%$. It was then assessed if PEN (1 mM) could be included in existing ram sperm capacitation protocols (TALP $+1 \mathrm{mM}$ dibutyryl cAMP, caffeine and theophylline) to produce spermatozoa that were simultaneously capacitated and non-agglutinated. This protocol resulted in a sperm population which displayed high levels of tyrosine phosphorylated proteins and lipid disordered membranes (merocyanine-540) while remaining motile, viable, acrosome-intact and non-agglutinated. In summary, PEN (1 $\mathrm{mM})$ can be included in ram sperm capacitation protocols to reduce sperm agglutination and allow for the in vitro assessment of ram sperm capacitation.

Reproduction (2016) 151 167-177
\end{abstract}

\section{Introduction}

Capacitation is the final maturation event that spermatozoa must undergo to develop the molecular, physiological and morphological attributes required for penetration of the oocyte (Chang 1984). Under this broad definition capacitation is not a concrete event, but a window in time which culminates in either fertilisation or death. The regulation of capacitation is principally thought to rely on extracellular factors, and in vitro capacitation media have been designed that mimic the oviductal environment where this process is induced (Leahy \& Gadella 2011). In addition to general electrolytes (e.g. $\mathrm{KCl}, \mathrm{MgCl}_{2}$ and $\mathrm{NaCl}$ ) and energy sources (e.g. pyruvate, lactate and glucose), capacitating media typically contain three key ingredients: bicarbonate $(15-25 \mathrm{mM})$, calcium $(1-3 \mathrm{mM})$ and fatty acid free serum albumin $(1-10 \mathrm{mg} / \mathrm{ml})$. Bicarbonate activates a soluble adenylate cyclase (sAC) which produces cAMP that then initiates a complex signal transduction cascade through the mediation of protein kinase A (PKA). The latter, in turn, stimulates a global increase in protein tyrosine phosphorylation that drives the process of capacitation (Aitken et al. 1998, Visconti et al. 1998). Bicarbonate also underlies the scrambling and lateral redistribution of sperm membrane lipids. For example, it is required for a partial scrambling of the phospholipids, phosphatidyl ethanolamine (PE) and phosphatidylserine (PS), which results in higher fluidity of the plasma membrane (which can be detected with the fluorescent stain merocyanine 540) and increased fusogenicity (Harrison \& Gadella 2005). There is also a lateral translocation of sperm membrane sterols from the equatorial region of the sperm head to the apical ridge (Flesch et al. 2001) where it is exported to cholesterol acceptors in the extracellular fluid. Under in vitro conditions, fatty acid free albumin is included in capacitating media to fulfil this function. The final ingredient, calcium, is required for a variety of cellular functions including hyperactivation (Correia et al. 2015) and induction of the acrosome reaction following binding of the spermatozoon to the zona pellucida (Jin et al. 2011, Yanagimachi 2011).

IVF success is well documented in some species, such as the mouse and human (Whittingham 1968, Mukherjee \& Cohen 1970) but this has not been the case for others 
(e.g. the stallion; (Bromfield et al. 2014)). There are considerable differences in sperm morphology and physiology across mammalian species, so it is not surprising that distinct species-specific capacitation phenomena also occur. Capacitation protocols can be tailored to specific species through the inclusion of additional factors which support capacitation. Ram spermatozoa have proven to be difficult to capacitate in vitro and require supplementation with both dibutyryl-cAMP (db-cAMP) and phosphodiesterase (PDE) inhibitors to stimulate the CAMP pathway and achieve maximal tyrosine phosphorylation of sperm proteins (Colas et al. 2008). Ram spermatozoa also show a unique requirement for sheep serum to be present in the fertilising medium for IVF success (Huneau et al. 1994, $\mathrm{Li}$ et al. 2006) as TALP alone does not stimulate cholesterol efflux in this species (Huneau et al. 1994, Colas et al. 2008, Leahy \& Gadella 2015). Another example is the addition of the highly negatively charged glycosaminoglycan heparin to bovine IVF protocols (Parrish et al. 1988). Heparin is thought to enhance fertilisation by facilitating the stripping of extracellular glycoproteins from the sperm surface, possibly mimicking the surface effects elicited by glycosaminoglycans present in oviductal fluids (Parrish et al. 1989, Coy et al. 2008, Killian 2011).

Many of the factors that have been shown to stimulate capacitation can also cause head-to-head agglutination of spermatozoa. For example, heparin, sheep serum or follicular fluid has been reported to cause head-to-head agglutination of spermatozoa under in vitro conditions in numerous species (monkey (Boatman \& Bavister 1984), bull (Ehrenwald et al. 1990, Lefebvre \& Suarez 1996), pig (Funahashi \& Day 1993)). These findings were extended in utero by Brown \& Senger (1982) who placed rabbit spermatozoa into the uterine lumen and noted significant agglutination of motile spermatozoa. Similar effects have been reported in the stallion with the use of BSA under capacitating conditions, so it is commonly substituted with polyvinyl alcohol (PVA; Bromfield et al. 2014).

Sperm head-to-head association has also been reported in media containing bicarbonate and divalent cations such as calcium (boar (Harayama et al. 1998, Harayama \& Kato 2002), bull (Lindahl \& Sjöblom 1981), monkey (Boatman \& Bavister 1984)). The agglutination response was increased by db-cAMP or selective inhibitors of CAMP-specific PDEs indicating this form of agglutination is mediated by a cAMP signalling cascade.

It is uncertain if this agglutination phenomena is physiologically relevant or an artefact created by the in vitro culture conditions in current usage. Agglutination is problematic in vitro because it interferes with sperm handling and analysis. For example technologies that require the analysis of single cells, such as flow cytometers or computer assisted motility analysis, cannot be used. A better understanding of the underlying mechanisms for sperm agglutination would lead to the development of novel anti-agglutination agents to allow the in vitro analysis of agglutinated spermatozoa and may shed light on the physiological relevance of autologous and heterologous cell binding to fertilisation. Thus, the objectives of the current study were to investigate the cause of sperm agglutination, the underlying biochemical mechanisms, as well as potential agents which may reduce sperm agglutination.

\section{Materials and methods}

\section{Chemicals}

Unless otherwise stated, products were sourced from SigmaAldrich and were of the highest reagent grade available. The base medium used for Experiments 1 and 2 was modified Tyrodes medium supplemented with albumin, lactate and pyruvate (TALP) (Parrish et al. 1988) which consisted of $2 \mathrm{mM}$ $\mathrm{CaCl}_{2}, 3.1 \mathrm{mM} \mathrm{KCl}, 0.4 \mathrm{mM} \mathrm{MgCl}, 95 \mathrm{mM} \mathrm{NaCl}, 0.3 \mathrm{mM}$ $\mathrm{NaH}_{2} \mathrm{PO}_{4}, 10 \mathrm{mM}$ HEPES, $21.6 \mathrm{mM}$ Na lactate, $5 \mathrm{mM}$ glucose, $1 \mathrm{mM}$ Na pyruvate, $25 \mathrm{mM} \mathrm{NaHCO}_{3}, 0.03 \mathrm{mM}$ phenol red and $3 \mathrm{mg} / \mathrm{ml}$ BSA.

In Experiment 3 the fertilising medium synthetic oviductal fluid (SOF) (Tervit et al. 1972) was used and consisted of $1.7 \mathrm{mM}$ $\mathrm{CaCl}_{2}, 7.2 \mathrm{mM} \mathrm{KCl}, 0.5 \mathrm{mM} \mathrm{MgCl} 2,107.7 \mathrm{mM} \mathrm{NaCl}, 1.2 \mathrm{mM}$ $\mathrm{KH}_{2} \mathrm{PO}_{4}, 3.3 \mathrm{mM}$ Na lactate, $1.5 \mathrm{mM}$ glucose, $0.3 \mathrm{mM} \mathrm{Na}$ pyruvate, $25.1 \mathrm{mM} \mathrm{NaHCO}, 0.03 \mathrm{mM}$ phenol red and $3 \mathrm{mg} / \mathrm{ml}$ BSA. For Experiment 4 the TALP medium was modified by lowering the bicarbonate concentration from $25 \mathrm{mM}$ to $15 \mathrm{mM}$ and increasing the HEPES concentration from $10 \mathrm{mM}$ to $40 \mathrm{mM}$. This modification was included to prevent sudden changes in $\mathrm{pH}$ when analysing small aliquots of spermatozoa in TALP.

\section{Sperm preparation}

Ram semen was collected from two Merino rams and one Merino Cross ram $(n=3)$ using an artificial vagina with project approval from the University of Sydney's Animal Ethics Committee (Project No: 2013/5854). Two ejaculates were collected from each ram, three times a week. Only ejaculates which had a wave motion score of 4 (out of 5) or higher were used in the study. The rams were kept on a chaff-based ration (oaten:Lucerne chaff, 1:1) supplemented with lupin grain in an animal house at the Faculty of Veterinary Science, University of Sydney, Camperdown, NSW, Australia. Experiments 1, 2 and 4 were carried out from January to June (breeding season) and Experiment 3 was carried out in October (non-breeding season).

In Experiments 1-3 neat semen was diluted to $50 \times 10^{6}$ spermatozoa $/ \mathrm{ml}$ and held for $3 \mathrm{~h}$ at $38.5{ }^{\circ} \mathrm{C}$ in a $5 \% \mathrm{CO}_{2}$ incubator. In Experiment 4 neat semen was extended tenfold in TALP and centrifuged at $600 \mathrm{~g}$ for $10 \mathrm{~min}$ to remove seminal plasma prior to dilution. Samples were then extended to $50 \times 10^{6} \mathrm{sperm} / \mathrm{ml}$ and held for $3 \mathrm{~h}$ at $38.5^{\circ} \mathrm{C}$ in a $5 \% \mathrm{CO}_{2}$ incubator. Substitutions or additions to the base TALP or SOF medium were made as outlined in 'Experimental design'. Where necessary, the $\mathrm{pH}$ was adjusted with $\mathrm{NaOH}$ and osmolarity adjusted with $\mathrm{NaCl}$ so the final $\mathrm{pH}$ and osmolarity of the various diluents was between 7.3-7.4 and 300-320 $\mathrm{mOsm} / \mathrm{l}$ respectively. 


\section{Experimental design}

Each experiment was replicated six times using two separate ejaculates from three Merino rams. Samples were assessed immediately after dilution and after $3 \mathrm{~h}$ of incubation.

\section{Experiment 1}

Experiment 1 was designed to assess the effect of specific TALP components on the agglutination of ram spermatozoa. Complete TALP was compared to TALP medium devoid of either calcium chloride (3 mM), sodium bicarbonate $(25 \mathrm{mM})$ or BSA $(3 \mathrm{mg} / \mathrm{ml})$. Osmolarity was balanced across the treatments by substitution with an equimolar concentration of $\mathrm{NaCl}, \mathrm{pH}$ was balanced with $\mathrm{NaOH}$ and BSA was replaced with $1 \%$ PVA.

\section{Experiment 2}

Experiment 2 was designed to assess the ability of PEN to prevent or revert the agglutination of ram spermatozoa in TALP. In Experiment 2a, spermatozoa were extended in TALP supplemented with PEN to a final concentration of $0,0.025$, $0.25,0.5$ or $1 \mathrm{mM}$. In Experiment $2 \mathrm{~b}$, spermatozoa were extended in TALP alone or in TALP which was supplemented with $1 \mathrm{mM}$ PEN either before or after sperm dilution.

\section{Experiment 3}

The aim of Experiment 3 was to test the effect of PEN in media designed for the IVF of ram spermatozoa (Morton et al. 2005a). Spermatozoa were diluted in SOF alone or SOF $+1 \mathrm{mM} \mathrm{PEN}$ supplemented with $0,2.5 \%$ or $10 \%$ heat inactivated $\left(56{ }^{\circ} \mathrm{C}\right.$, $30 \mathrm{~min}$ ) sheep serum (Sigma-Aldrich).

\section{Experiment 4}

The aim of Experiment 4 was to test the effect of the presence or absence of $1 \mathrm{mM}$ PEN on the in vitro capacitation of spermatozoa incubated for 0 (TALP $0 \mathrm{~h}$; Control) or $3 \mathrm{~h}$ in TALP (TALP $3 \mathrm{~h}$ ) or TALP supplemented with $1 \mathrm{mM}$ of the following: $\mathrm{db}$-cAMP, caffeine and theophylline (TALP $3 \mathrm{~h}+$ CAP STIM). The detection of tyrosine phosphorylation of sperm proteins by western blot analysis was used as a marker of the capacitation process as this test could be performed on agglutinated spermatozoa. The methods are described below in 'Extraction of ram sperm proteins' and 'SDS-PAGE and western blot protocol'. Supplementing the samples with $1 \mathrm{mM}$ PEN prevented agglutination and allowed a wider range of functional markers that rely on single cell analysis to be utilised. These are described below in 'Sperm motility and kinematics' and 'Flow cytometric evaluation of sperm function'. Samples which were not supplemented with PEN could not be assessed using these techniques due to their agglutinated state.

\section{Sperm auto-agglutination assay}

Spermatozoa $(15 \mu \mathrm{l})$ were placed on a glass slide (Livingstone International, Sydney, Australia) under a $22 \times 50 \mathrm{~mm}$ coverslip (Livingstone) and observed on a warm stage $\left(37^{\circ} \mathrm{C}\right)$ under light microscopy using phase contrast optics
(400× magnification) with an Olympus (Macquarie Park, NSW, Australia) BX51 microscope equipped with an Olympus DP73 digital camera. Four fields of view were recorded over $1 \mathrm{~min}$. Samples were randomised and coded so the assessor was blind to sample treatment. The videos were watched frame by frame using the Olympus cellSens imaging software. Spermatozoa (200 cells counted per sample) were assigned one of four categories: motile and non-agglutinated, motile and agglutinated, non-motile and non-agglutinated or non-motile and agglutinated.

\section{Sperm motility and kinematics}

Sperm motility and kinematics were objectively evaluated by computer-assisted sperm analysis (HT CASA IVOS II (Animal Breeder) Version 1.4; Hamilton-Thorne, Beverly, MA, USA) using factory CASA ram settings. Semen samples $(5.5 \mu \mathrm{l})$ were placed on prewarmed slides $37^{\circ} \mathrm{C}$ (Cell Vu; Millenium Sciences, Mulgrave, Vic., Australia) and enclosed using a $22 \times 22 \mathrm{~mm}$ coverslip before immediate transfer to the CASA. A minimum of 300 spermatozoa were observed from at least five randomly selected fields. Recorded parameters were: total motile spermatozoa (\%), progressively motile spermatozoa (\%), straight-line velocity (VSL, $\mu \mathrm{m} / \mathrm{s})$, curvilinear velocity $(\mathrm{VCL}$, $\mu \mathrm{m} / \mathrm{s})$, average-path velocity (VAP, $\mu \mathrm{m} / \mathrm{s})$, amplitude of lateral head displacement $(\mathrm{ALH}, \mu \mathrm{m})$, beat-cross frequency $(\mathrm{BCF}, \mathrm{Hz})$, linearity (LIN, \%) and straightness (STR, \%).

\section{Flow cytometric evaluation of sperm function}

An Accuri cytometer with a standard argon ion laser $(488 \mathrm{~nm}$; Accuri C6; BD Accuri Cytometers, Ann Arbor, MI, USA) and BD ACCURI software was used for analysis. A total of 10000 spermatozoa were assessed per sample. Viability and acrosome integrity were determined by dual fluorescence staining for $10 \mathrm{~min}$ at $37^{\circ} \mathrm{C}$ with $6 \mu \mathrm{M}$ propidium iodide (PI; Invitrogen) and $0.4 \mathrm{mg} / \mathrm{ml}$ fluorescein isothiocyanate-peanut agglutinin (FITC-PNA). Membrane lipid order and viability were assessed through dual fluorescent staining for $10 \mathrm{~min}$ at $37^{\circ} \mathrm{C}$ with $0.83 \mu \mathrm{M}$ merocyanine 540 (M540) and $25 \mathrm{~nm}$ Yo-Pro (Molecular Probes, Eugene, OR, USA).

\section{Extraction of ram sperm proteins}

Aliquots of $10 \times 10^{6}$ spermatozoa were washed twice $(600 \mathrm{~g}$, $10 \mathrm{~min}$ ) in BSA-free TALP to reduce the concentration of BSA in the medium. The sperm pellet was then resuspended in $30 \mu \mathrm{l}$ of lysis buffer $(62.6 \mathrm{mM}$ Tris, $1 \mathrm{mM}$ orthovanadate, $2 \% \mathrm{w} / \mathrm{v}$ SDS, complete ultra mini EDTA-free protease inhibitor tablet (Roche Diagnostics)) and kept at room temperature for $1 \mathrm{~h}$ with frequent vortexing. The samples were then centrifuged $(7500 \mathrm{~g}$, $15 \mathrm{~min}$ ) and the supernatant retained. Protein concentration was estimated using a bicinchoninic acid assay (BCA; Pierce, Chester, UK) and standardised with Milli-Q water before dilution with loading buffer to a final concentration of $62.5 \mathrm{mM}$ Tris, $\mathrm{pH} 6.8 ; 5 \%(\mathrm{v} / \mathrm{v})$ 2-mercaptoethanol; 2\% (v/v) SDS; $10 \%$ glycerol $(\mathrm{v} / \mathrm{v}) ; 0.2 \%(\mathrm{w} / \mathrm{v})$ bromophenol blue. Samples were then incubated for $5 \mathrm{~min}$ at $95^{\circ} \mathrm{C}$ and stored at $-80{ }^{\circ} \mathrm{C}$ until required. 


\section{SDS-PAGE and western blot}

Unless otherwise specified, all reagents and equipment used for SDS-PAGE and western blot analysis were purchased from Bio-Rad. Precision plus Kaleidoscope standards, MagicMark XP Western Protein Standards (Life Technologies) and sperm protein extracts $(30 \mu \mathrm{g})$ were loaded onto $10 \%$ Mini-PROTEAN TGX stain free gels and electrophoresis was carried out at $200 \mathrm{~V}$. To validate gel loading, quantification of protein bands was achieved using a stain-free analysis protocol on a Chemi-Doc MP Imaging System. Proteins were then transferred to an Immuno-Blot PVDF membrane at $100 \mathrm{~V}$ for $1 \mathrm{~h}$ in Towbins transfer buffer $(25 \mathrm{mM}$ Tris, $192 \mathrm{mM}$ glycine, 15\% methanol $(\mathrm{v} / \mathrm{v})$ ). Ponceau S concentrate (Sigma-Aldrich) was used to check transfer. Non-specific sites on the membrane were blocked for $1 \mathrm{~h}$ in Tris buffered saline (20 mM Tris, $150 \mathrm{mM} \mathrm{NaCl}, \mathrm{pH} 7.6$ ) supplemented with $0.1 \%$ Tween 20 (TBS-T) containing 5\% (w/v) BSA (Sigma-Aldrich). Blots were incubated with a MAB HRPconjugated anti-phosphotyrosine (monoclonal Ab; clone 4G10, Upstate, Santa Cruz, CA, USA, Cat. no. 16-105), diluted 1:2000 in TBS-T+0.1\%BSA $(\mathrm{w} / \mathrm{v}))$ with agitation, for $1 \mathrm{~h}$ at room temperature. After washing $(3 \times 15 \mathrm{~min}$ with TBS-T), proteins were visualised on a Chemi-doc system using enhanced chemiluminescence (Clarity) as per manufacturer's instructions. Each treatment was replicated six times (three biological replicates (rams) $\times$ two technical replicates).

\section{Statistical analysis}

Statistical analysis was performed using linear mixed models regression in GENSTAT (version 16; VSN International, Hemel Hempstead, UK). Interactions between treatment effects and time were assessed with ejaculate and ram incorporated into the blocking structure. Data are presented as the model-derived mean \pm S.E.M. Results are expressed as significant $(* P<0.05)$ and highly significant $\left({ }^{* *} P<0.001\right)$ compared to control samples.

\section{Results}

\section{TALP causes a specific and persistent agglutination of ram spermatozoa}

Dilution of fresh ram semen in TALP causes a rapid association of sperm membranes in the region overlying the acrosome. Sperm agglutination does not impair motility. In fact more than $95 \%$ of motile spermatozoa were agglutinated whereas the majority of non-motile

Table 1 Representative motility and agglutination patterns when ram sperm are diluted in TALP.

\begin{tabular}{lcccc}
\hline & $\begin{array}{c}\text { Non- } \\
\text { agglutinated, } \\
\text { motile \% }\end{array}$ & $\begin{array}{c}\text { Non- } \\
\text { agglutinated, } \\
\text { non-motile \% }\end{array}$ & $\begin{array}{c}\text { Agglutinated, } \\
\text { motile \% }\end{array}$ & $\begin{array}{c}\text { Agglutinated, } \\
\text { non-motile \% }\end{array}$ \\
\hline 0 & $3.5 \pm 1.5$ & $17.8 \pm 3.0$ & $76.3 \pm 3.8$ & $2.4 \pm 0.8$ \\
3 & $1.5 \pm 0.5$ & $18.6 \pm 4.0$ & $77.2 \pm 4.1$ & $2.7 \pm 0.4$ \\
\hline
\end{tabular}

Data correspond to model derived mean \pm s.E.M. for six independent samples from TALP only treatment in Experiment 2a.

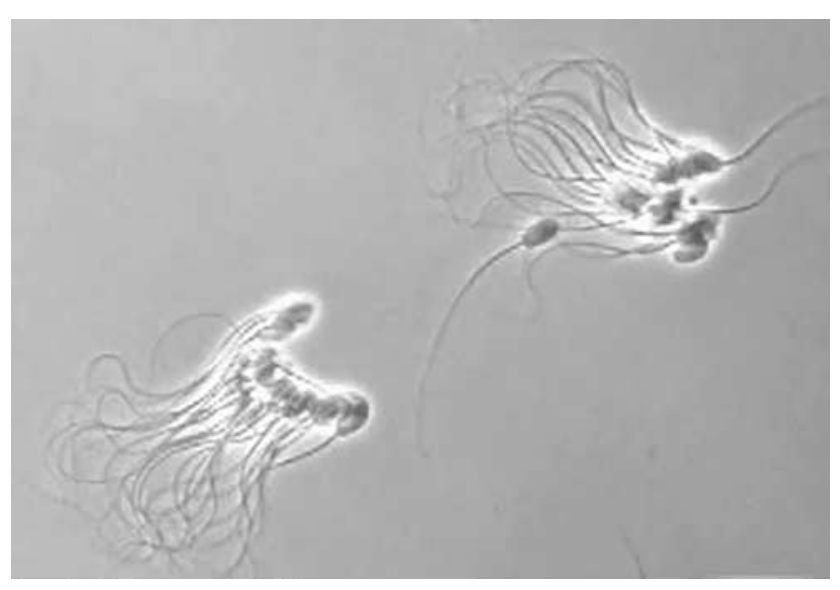

Figure $1 \mathrm{~A}$ representative image of agglutinated ram spermatozoa in TALP. Viewed under $400 \times$ magnification at $0 \mathrm{~h}$ of incubation.

spermatozoa existed as single cells (Table 1 ). At $0 \mathrm{~h}$ of analysis, aggregates usually consisted of 2-20 spermatozoa which were aligned in parallel due to their motile status and moved rapidly across the field of vision (Fig. 1 and Supplementary Video 1, see section on supplementary data given at the end of this article) to show the vigorous motility of agglutinated samples). Agglutination was persistent over the 3 -h incubation period (Table 1), after which time much larger circular clusters of spermatozoa had formed that limited progressive motility but the spermatozoa still displayed vigorous movement of their flagella. The phenomenon was highly consistent across replicates but did show some variation between rams in the extent of agglutination (speed at which agglutination formed, number of spermatozoa per cluster), although agglutination occurred with all rams tested. To rule out the chance of contamination through the use of in-house chemicals or water supply (Milli-Q) during TALP preparation, we compared it to fully prepared Tyrodes, purchased from Sigma-Aldrich (Cat no: T2397). This diluent also caused ram sperm agglutination (data not shown).

\section{Bicarbonate enhances ram sperm agglutination in TALP}

To investigate the causative agent of the agglutination of ram spermatozoa in TALP, single components of the medium were omitted. The three main capacitating components within TALP (bicarbonate ions, calcium ions and albumin) were chosen for testing. The omission of bicarbonate resulted in an increase in the percentage of non-agglutinated, motile spermatozoa, compared with spermatozoa in complete TALP (Fig. 2), and a corresponding decrease in the percentage of agglutinated, motile spermatozoa. The omission of calcium or albumin had no effect on the percentage of nonagglutinated spermatozoa (Fig. 2). 


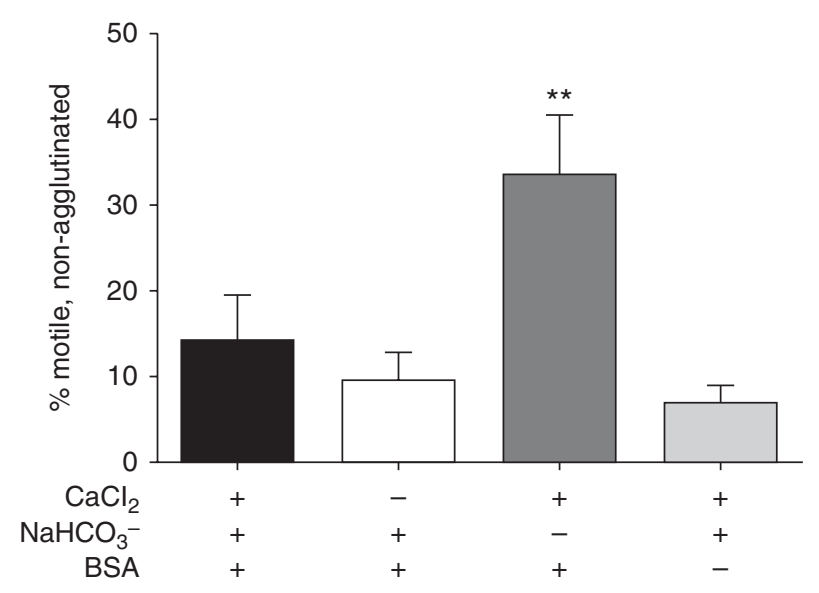

Figure 2 Bicarbonate enhances ram sperm agglutination in TALP. The omission of sodium bicarbonate $\left(\mathrm{NaHCO}_{3}{ }^{-}, 25 \mathrm{mM}\right.$, dark grey bar) from complete TALP (black bar) increased the percentage of motile, non-agglutinated spermatozoa whereas the omission of calcium chloride $\left(\mathrm{CaCl}_{2}, 2 \mathrm{mM}\right.$, open bar) or BSA ( $3 \mathrm{mg} / \mathrm{ml}$, light grey bar) had no effect. Data corresponds to model derived mean \pm S.E.M. of six independent samples. ${ }^{* *}$ indicates $P<0.001$ significantly different compared to control sample (complete TALP; black column).

\section{Penicillamine can dissociate bound spermatozoa and prevent sperm association in TALP}

BSA or PVA are commonly added to andrology media to prevent sperm sticking in a non-specific fashion to glass or plasticware but neither of these compounds (Fig. 2) prevented the specific head-to-head agglutination seen when ram spermatozoa were diluted in TALP.

There were anecdotal reports that the thiol, D-penicillamine (PEN), reduced agglutination of bull spermatozoa conferred by heparin or bovine serum (Pavlok 2000, Pavlok et al. 2001) so this compound was included in TALP to assess its anti-agglutination properties. The PEN doses utilised ranged from a low level $(0.025 \mathrm{mM})$ previously used in culture medium for bovine IVF (Gordon 2003) to a mid-range dose $(0.5 \mathrm{mM})$, previously used in hamster capacitation (Andrews \& Bavister 1989), to higher levels (1 mM) used to protect stallion spermatozoa from oxidative stress in ambient storage media (Aitken et al. 2012). PEN was a highly effective anti-agglutination agent (Fig. 3) which increased the proportion of non-agglutinated, motile spermatozoa and decreased the proportion of agglutinated, motile spermatozoa. A dose of $0.25 \mathrm{mM}$ was sufficient to reduce the agglutinated population by $96 \%$ and this effect was sustained across the 3 -h test period.

After it was shown that PEN could prevent the agglutination of ram spermatozoa when included in TALP, we assessed if PEN could reverse TALP-induced sperm agglutination. The positive control for this experiment involved ram spermatozoa diluted in TALP, which were highly agglutinated (Fig. 4a; Supplementary
Video 1), while the negative control comprised semen extended with TALP in which sperm agglutination had been prevented by the inclusion of $1 \mathrm{mM}$ PEN (Fig. 4b; Supplementary Video 2) to show the vigorous motility of agglutinated samples). In the experimental group, the spermatozoa were allowed to agglutinate and then PEN was added to a final concentration of $1 \mathrm{mM}$, followed by a reassessment $3 \mathrm{~min}$ later (Fig. 4c; Supplementary Video 3). The addition of PEN (1 mM) to agglutinated spermatozoa induced rapid dissociation, increasing the percentage of non-agglutinated motile spermatozoa from $3.2 \pm 1.7 \%$ to $59.0 \pm 8.0 \%$ and reducing the number of agglutinated spermatozoa per aggregate (Fig. 4c; Supplementary Video 3). This was however lower than the percentage of non-agglutinated, motile spermatozoa in samples which had been initially diluted in TALP containing PEN (79.8 $\pm 2.2 \%$; Fig. $4 \mathrm{~b})$. This weaker response may have been caused by the short time frame in which PEN had to act on spermatozoa as they were only co-incubated for 3 min prior to analysis.

\section{Penicillamine can prevent sperm agglutination in SOF and agglutination caused by low doses of sheep serum}

The agglutination of ram spermatozoa during IVF is a common occurrence and is thought to be caused by the inclusion of sheep serum $(\sim 2-20 \%)$ in fertilising media such as SOF. We tested if PEN could also prevent agglutination under routine ovine IVF conditions. The dilution of fresh ram semen in SOF caused a rapid association of sperm membranes in the region overlying the acrosome that was very similar to the response seen in TALP (Fig. 5). The inclusion of PEN in SOF was also

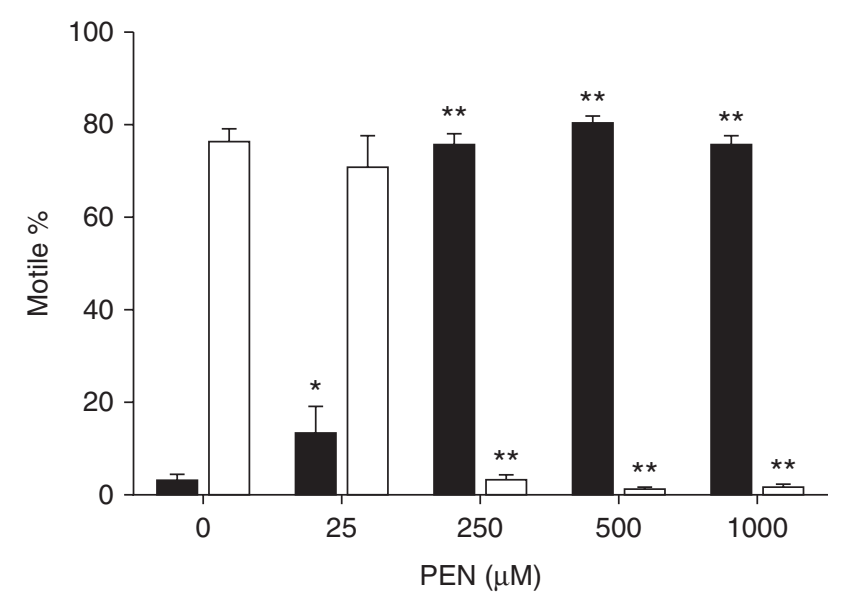

Figure 3 Penicillamine (PEN) prevents sperm agglutination in TALP. The inclusion of PEN in the TALP medium showed a strong dose response on ram sperm agglutination. PEN increased the percentage of motile, non-agglutinated spermatozoa (black bars) and decreased the percentage of motile, agglutinated spermatozoa (open bars). Data correspond to model derived mean \pm s.E.M. for six independent samples. *Indicates $P<0.05$ and **indicates $P<0.001$ significantly different compared to control sample $(0 \mu \mathrm{M})$ within sperm category. 

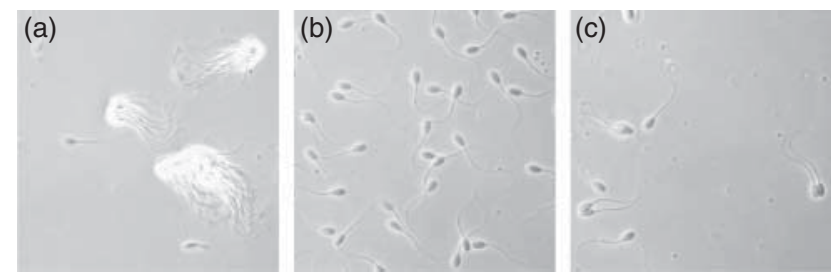

Figure 4 Penicillamine (PEN) can dissociate bound spermatozoa and prevent sperm association in TALP. Representative frames taken from the analysed video files which show (a) ram sperm agglutination in TALP, (b) free swimming spermatozoa extended in TALP + 1 mM PEN and (c) disassociation of agglutinated spermatozoa 3 min after the introduction of $1 \mathrm{mM}$ PEN. The three frames are from the same ram at $0 \mathrm{~h}$ viewed under $400 \times$ magnification. The associated video files are included in supplementary information (Supplementary Videos 1,2 and 3.

able to prevent SOF-induced ram sperm agglutination. Minimal $(1.2 \%)$ agglutination of motile spermatozoa was also observed when $2.5 \%$ sheep serum was included in SOF $+1 \mathrm{mM}$ PEN but the higher dose of $10 \%$ sheep serum increased $(P>0.05)$ the percentage of motile, agglutinated sperm (26.3\%).

\section{PEN can be successfully included in ram sperm capacitation protocols}

Agglutination is undesirable in vitro because it makes sperm handling difficult and is not compatible with sperm assays that rely on the analysis of single cells (e.g. CASA, flow cytometry). Here we tested if PEN could be included in ram sperm capacitation protocols to allow the in vitro analysis of capacitation markers. As discussed earlier, ram spermatozoa are not capacitated by standard capacitating media such as TALP and require additional factors that upregulate cAMP (Colas et al. 2008). We compared TALP at $0 \mathrm{~h}$ (control; TALP $0 \mathrm{~h}$ ) to TALP at $3 \mathrm{~h}$ incubated in the absence (TALP $3 \mathrm{~h}$ ) or presence of $1 \mathrm{mM} \mathrm{db}$-cAMP, caffeine and theophylline (TALP $3 \mathrm{~h}+$ CAP STIM). In the previous experiment a dose of $0.25 \mathrm{mM}$ PEN was sufficient to abolish agglutination in TALP. Interestingly, when $1 \mathrm{mM}$ $\mathrm{db}$-cAMP, caffeine and theophylline were supplemented to TALP, a higher dose of $1 \mathrm{mM}$ PEN was required to prevent sperm agglutination (data not shown). This suggests that agglutination is stimulated by the cAMP pathway and supports our earlier findings that agglutination is enhanced by bicarbonate.

Western blot analysis in the presence or absence of PEN $(1 \mathrm{mM})$ demonstrated that the addition of PEN had no significant effect on sperm protein tyrosine phosphorylation under any of the assayed conditions (Fig. 6a and $b$ ). The total band intensity in the presence (554 861 \pm 48618 ) or absence (555 619 \pm 47 870) of PEN was very similar. PEN showed no statistical difference in band intensity across all treatments with the exception of a $220+\mathrm{kDa}$ band (indicated by an arrow in Fig. 6) in the TALP $3 \mathrm{~h}+$ CAP STIM treatment which showed greater $(P<0.05)$ phosphorylation in the presence (515 140 \pm 84717 ) of PEN than in its absence (331639 \pm 55258$)$. These results suggest that PEN $(1 \mathrm{mM})$ does not interfere in the capacitation process and can be included in ram sperm capacitation protocols.

Three notable phosphorylation patterns were evident across the treatments (volume intensity of bands shown in Supplementary Table 1, see section on supplementary data given at the end of this article). A low molecular weight protein band $(22 \mathrm{kDa})$ was phosphorylated in TALP after $3 \mathrm{~h}$ in the presence or absence of the stimulating agents (db-cAMP, PDE inhibitors) but not at $0 \mathrm{~h}$. Mid-range molecular weight proteins $(41,47 \mathrm{kDa})$ were constitutively phosphorylated across all treatments but phosphorylation of higher molecular weight proteins $(56+\mathrm{kDa})$ only occurred in the presence of cAMP stimulating agents (db-cAMP, PDE inhibitors). These confirm earlier findings that db-cAMP and PDE inhibitors should be used to achieve maximal phosphorylation of higher molecular weight proteins in ram spermatozoa (Colas et al. 2008).

The inclusion of PEN in the capacitating medium prevented sperm agglutination and allowed a wider array of functional assays that analyse single cells (e.g. CASA and flow cytometry) to be employed. M540 was used as an indicator of membrane order and spermatozoa were counter-stained with Yo-Pro to detect viability. The present study showed that the lipid order of ram spermatozoa was not effected by a 3 -h incubation in TALP but a high proportion of viable, lipid disordered

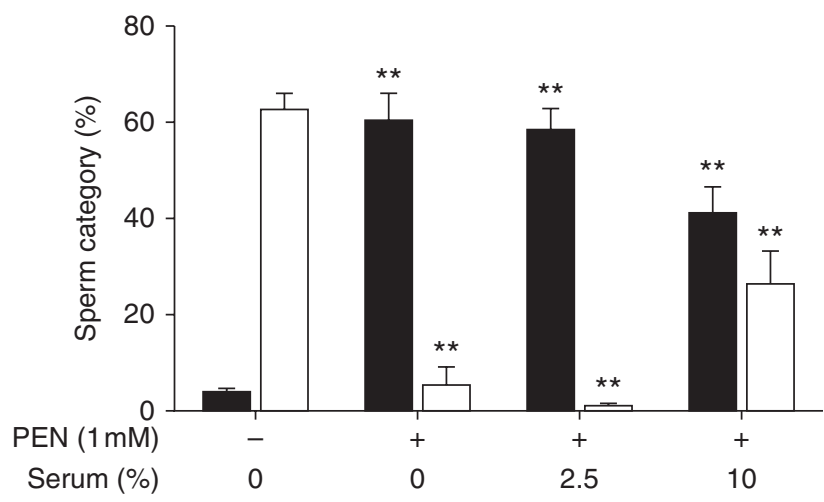

Figure 5 Penicillamine (PEN) prevents sperm agglutination in SOF and agglutination caused by low doses of sheep serum. Dilution in the fertilising medium synthetic oviductal fluid (SOF) caused rapid agglutination of motile ram spermatozoa (open bars). PEN (1 mM) significantly increased the percentage of motile, non-agglutinated spermatozoa (black bars) and decreased the percentage of motile, agglutinated spermatozoa. Minimal agglutination of motile spermatozoa was observed with $2.5 \%$ sheep serum but the higher dose of $10 \%$ sheep serum increased the percentage of motile, agglutinated sperm. Data correspond to model derived mean \pm s.E.M. for six independent samples. **indicates $P<0.001$ significantly different compared to control sample (no PEN, no serum) within treatment. 

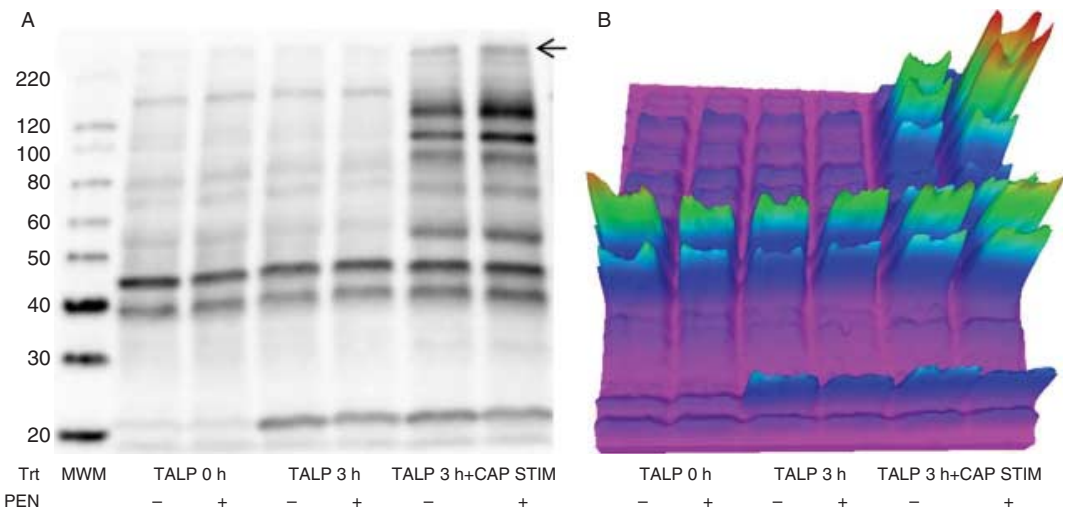

Figure 6 Penicillamine (PEN) does not inhibit capacitation-related protein tyrosine phosphorylation but maximal phosphorylation of higher molecular weight sperm proteins requires CAMP and PDE inhibitors. Western-blot analysis of protein tyrosine phosphorylation of ram sperm proteins incubated $\left(38.5{ }^{\circ} \mathrm{C}, 5 \% \mathrm{CO}_{2}\right)$ with or without $1 \mathrm{mM}$ PEN for $0 \mathrm{~h}$ in TALP (TALP $0 \mathrm{~h}$; control) or for $3 \mathrm{~h}$ in TALP (TALP $3 \mathrm{~h}$ ) or TALP supplemented with $1 \mathrm{mM} \mathrm{db}$-cAMP, theophylline and caffeine (TALP $3 \mathrm{~h}+$ CAP STIM). Proteins were extracted, analysed by SDS-PAGE and western blotting of phosphotyrosine residues performed (4G10 monoclonal Ab). The experiment was performed six times and a representative membrane (a) and a 3D representation (Image Lab, Bio-Rad) of band volume (b) is shown. Arrow indicates a $220+\mathrm{kDa}$ band which showed greater $(P<0.05)$ phosphorylation in the presence of PEN than in its absence in the TALP $3 \mathrm{~h}+$ CAP STIM treatment.

spermatozoa were evident upon the upregulation of cAMP through the inclusion of $1 \mathrm{mM}$ db-cAMP, caffeine and theophylline (Fig. 7a). Incubation for $3 \mathrm{~h}$ with these agents also increased the amount of lipid disordered, non-viable spermatozoa compared to TALP alone (Fig. 7a).

Viability and acrosome status was assessed using dual staining with PI and FITC-PNA (Fig. 7b). The percentage of viable and acrosome intact spermatozoa did not vary between 0 and $3 \mathrm{~h}$ in TALP. The addition of $1 \mathrm{mM}$ $\mathrm{db}$-cAMP, caffeine and theophylline increased the percentage of non-viable, acrosome reacted cells but over half of the sperm population $(50.8 \pm 5.7 \%)$ were still viable and acrosome intact after $3 \mathrm{~h}$ of incubation.

Total and progressive motility remained high over the $3 \mathrm{~h}$ incubation period in all treatments (Table 2). Despite showing other markers of capacitation, TALP $3 \mathrm{~h}+$ CAP STIM (Table 2) did not display signs of hyperactivation, such as decreased linearity from asymmetrical flagellar beating, high-amplitude head movements (ALH) or increased curvilinear velocity (Kay \& Robertson 1998). This correlates with earlier studies in the ram (Colas et al. 2010) and bull (Marquez \& Suarez 2004) which suggest that hyperactivation is not linked to the CAMP pathway or tyrosine phosphorylation.

\section{Discussion}

Many species-specific capacitation phenomena have been described. Here we report that ram sperm agglutinate when diluted in the commonly used capacitating media TALP and SOF. To our knowledge this is the first report of this phenomenon, which is curious considering the common use of these diluents for the dilution of ram semen. The association is rapid and persistent and occurs in a head-to-head fashion in the area overlying the acrosome (Figs 1, 4, 5 and Supplementary Video 1). The high occurrence of agglutination in the sperm population suggests a strong reactivity of the ram sperm membrane to components of the TALP medium. Spermatozoa, like other biocolloids, exhibit a tendency to flocculate (agglutinate) in response to a variety of physico-chemical stimuli. Many of these, including high dilution or washing, cold shock, extreme $\mathrm{pH}$ or osmotic conditions result in the loss of sperm function (Mann 1964). TALP-induced sperm agglutination does not. In fact, motile spermatozoa were far more likely to be agglutinated than non-motile spermatozoa (Table 1). This may be caused by the greater chance of cell-cell collision within the motile population but is more likely to be due to the requirement of an intact functional plasma membrane for binding, as previously reported in bull spermatozoa when exposed to serum in vitro (Aalseth et al. 1978) or in vivo (Brown \& Senger 1982). Serum-induced agglutination of bull spermatozoa has even been thought to preserve sperm function as the acrosome integrity of agglutinated spermatozoa declined less rapidly over the 9-h test period compared to that of non-agglutinated spermatozoa (Senger \& Saacke 1976).

Sheep serum $(2-20 \%)$ is routinely included in the fertilising medium for ovine IVF as standard capacitating media (e.g. TALP, SOF) do not stimulate protein tyrosine phosphorylation and cholesterol efflux of ram spermatozoa (Huneau et al. 1994, Li et al. 2006, Colas et al. 2008, Leahy \& Gadella 2015). Since sheep serum has been previously reported to cause sperm agglutination (Senger \& Saacke 1976, Lindahl \& Sjöblom 1981, Senger et al. 1981), and SOF supplemented with serum (2-20\%) is the most commonly used sheep IVF fertilising medium, we tested if PEN could prevent agglutination in SOF medium containing $2.5 \%$ or $10 \%$ sheep serum. 

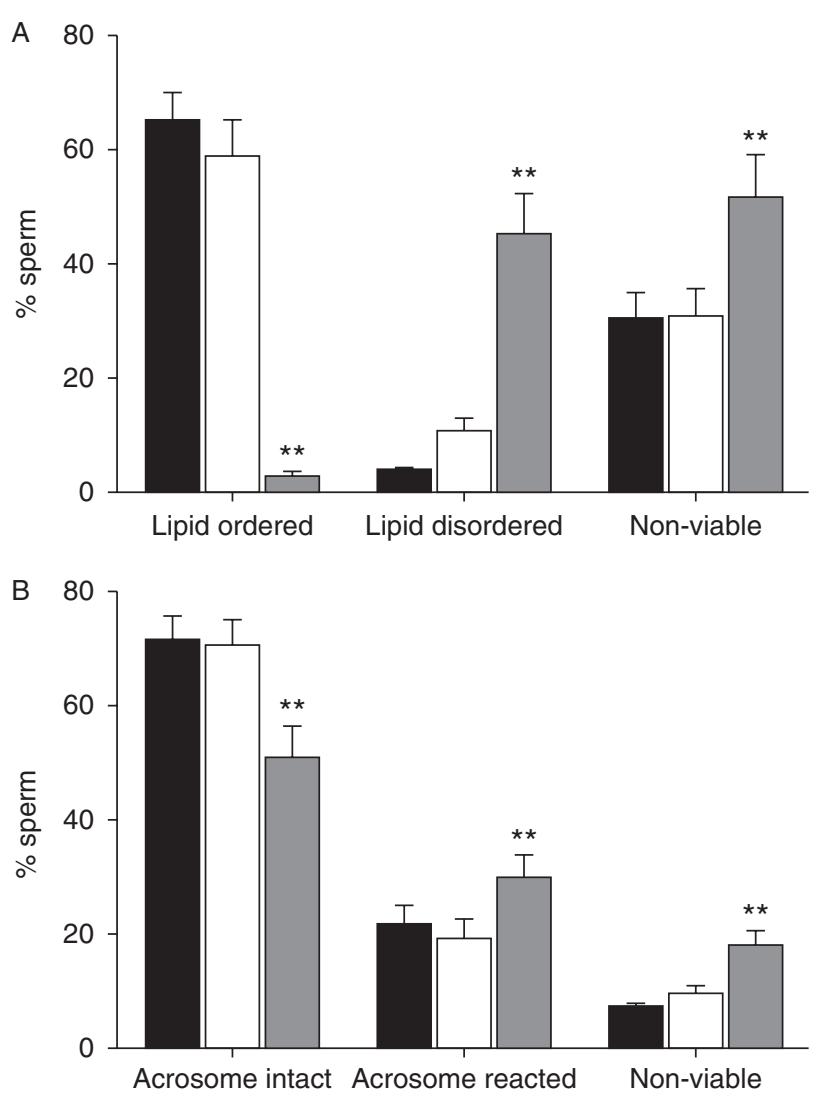

Figure 7 Upregulation of CAMP increases lipid disorder and the acrosome reaction. Penicillamine (PEN, $1 \mathrm{mM}$ ) was supplemented to TALP and spermatozoa were assessed at 0 (control; black bars) and $3 \mathrm{~h}$ (open bars) and this was compared to sperm incubated for $3 \mathrm{~h}$ in TALP supplemented with $1 \mathrm{mM}$ PEN, db-cAMP, caffeine and theophylline (grey bars). Lipid order (merocyanine 540 (M540)) and viability (Yo-Pro) were assessed via dual staining and flow cytometry (a) to ascertain three populations: lipid ordered, viable (M540-, Yo-Pro-); lipid disordered, viable (M540+, Yo-Pro-); and non-viable (M540+, Yo-Pro+). Acrosome status (fluorescein isothiocyanate-peanut agglutinin (FITC-PNA)) and viability (propidium iodide (PI)) were assessed via dual staining and flow cytometry (b) to ascertain three populations: acrosome intact, viable (FITC-PNA - , PI - ; acrosome intact); acrosome reacted, non-viable (FITC-PNA+, $\mathrm{PI}+$; acrosome reacted); acrosome intact, non-viable (FITC-PNA - , PI+; non-viable). Data correspond to model derived mean \pm S.E.M. for six independent samples. ${ }^{* *} P<0.001$ indicate differences compared to control (TALP 0 h; black bars).

SOF alone resulted in ram sperm agglutination which is not surprising considering its composition is highly similar to that of TALP. PEN ( $1 \mathrm{mM}$ ) was able to prevent SOF-induced ram sperm agglutination and agglutination caused by low doses $(2.5 \%)$ of sheep serum. However, PEN was unable to maintain low levels of agglutination at the higher dose of $10 \%$ sheep serum. Since $2 \%$ sheep serum in SOF is commonly used for ram sperm IVF (Morton et al. 2005b, Casao et al. 2010) it would be interesting to assess if the agglutination status of ram spermatozoa in the fertilising medium influences the outcome of ovine IVF.
Sperm head-to-head association has also been previously reported to be stimulated by cAMP in the presence of divalent cations such as calcium (Lindahl \& Sjöblom 1981, Boatman \& Bavister 1984, Harayama et al. 1998, Harayama \& Kato 2002). In our experiments, evidence for a similar effect in the ram was shown by the increase in non-agglutinated, motile spermatozoa when bicarbonate was omitted from medium (Fig. 2). Further indirect evidence included the stronger association of spermatozoa, which required higher doses of PEN ( $1 \mathrm{mM}$ compared to $0.25 \mathrm{mM}$ ) to reverse agglutination, when db-cAMP and PDE inhibitors were included in the TALP medium. However, unlike the previous studies (Lindahl \& Sjöblom 1981, Harayama et al. 1998, Harayama \& Kato 2002, Yang et al. 2012), agglutination did not rely on the presence of calcium as the omission of calcium from the TALP medium had no effect on sperm agglutination (Fig. 2). Although other divalent cations in TALP which were not examined in the present study may have contributed to theagglutination effect (e.g. $\mathrm{MgCl}_{2}$ ).

PEN was shown to be a highly effective agent to either prevent or reverse TALP-induced agglutination of ram spermatozoa. A dose of $0.25 \mathrm{mM}$ prevented agglutination in $96 \%$ of the sperm population (Fig. 3) and higher doses $(1 \mathrm{mM})$ caused disassociation of agglutinated spermatozoa in under $3 \mathrm{~min}$ (Fig. 4). The effect of PEN persisted throughout the 3 -h test period and had no effect on total motility, only causing a shift in the motile population from an agglutinated state to a nonagglutinated state. PEN $(1 \mathrm{mM})$ also prevented agglutination in TALP supplemented with db-cAMP and PDE inhibitors and in SOF supplemented with or without $2.5 \%$ sheep serum. These characteristics make this compound well suited for in vitro use in sperm handling protocols. In fact, PEN has been previously reported to improve sperm function and fertility. Studies assessing the inclusion of low doses $(20 \mu \mathrm{M})$ of PEN for bovine IVF

Table 2 Motility characteristics assessed using computer-assisted sperm analysis (CASA).

\begin{tabular}{|c|c|c|c|}
\hline $\begin{array}{l}\text { Motility } \\
\text { characteristic }\end{array}$ & TALP $0 \mathrm{~h}$ & TALP $3 \mathrm{~h}$ & $\begin{array}{l}\text { TALP } 3 \mathbf{h}+ \\
\text { CAP STIM }\end{array}$ \\
\hline Total motility (\%) & $70.8 \pm 4.3$ & $84.2 \pm 2.1^{*}$ & $70.6 \pm 3.5$ \\
\hline $\begin{array}{l}\text { Progressive } \\
\text { motility (\%) }\end{array}$ & $64.9 \pm 3.9$ & $78.4 \pm 2.5^{*}$ & $60.6 \pm 5.0$ \\
\hline $\begin{array}{l}\text { Amplitude of lateral } \\
\text { head }(\mathrm{ALH})(\mu \mathrm{m})\end{array}$ & $5.2 \pm 0.3$ & $4.7 \pm 0.4$ & $3.8 \pm 0.5^{*}$ \\
\hline $\begin{array}{l}\text { Beat-cross frequency } \\
(\mathrm{BCF})(\mathrm{Hz})\end{array}$ & $41.0 \pm 1.0$ & $41.5 \pm 0$ & $24.9 \pm 0.7^{* *}$ \\
\hline Linearity (LIN) (\%) & $82.0 \pm 1.3$ & $82.0 \pm 1.7$ & $91.0 \pm 2.8^{* *}$ \\
\hline $\begin{array}{l}\text { Curvilinear velocity } \\
(\mathrm{VCL})(\mu \mathrm{m} / \mathrm{s})\end{array}$ & $219.0 \pm 12.4$ & $182.8 \pm 9.9^{*}$ & $161.0 \pm 12.4^{* *}$ \\
\hline $\begin{array}{l}\text { Straight-line velocity } \\
\text { (VSL) }(\mu \mathrm{m} / \mathrm{s})\end{array}$ & $177.6 \pm 10.2$ & $148.7 \pm 9.0^{*}$ & $145.1 \pm 8.9^{*}$ \\
\hline
\end{tabular}

Data correspond to model derived mean \pm s.E.M. for six independent samples. ${ }^{*} P<0.05,{ }^{* *} P<0.001$ indicate difference compared to TALP $0 \mathrm{~h}$. 
protocols (Gordon 2003) or higher doses (1-2 mM) for ambient storage of stallion spermatozoa (Aitken et al. 2012) reported a significant protective effect of PEN on the sperm fertile lifespan. Human studies also showed PEN increased the percentage of progressively motile human spermatozoa as well as increasing the linearity and straight line velocity of the population (Wroblewski et al. 2003).

Agents that reduce autologous sperm agglutination are not well described and the mechanism by which PEN prevent or reverts sperm association is not understood. PEN contains three functional groups; an amine, a carboxyl group and a sulfhydryl. Of these, the sulfhydryl group is of greatest biological significance as it can combine with a multitude of compounds and participate in redox reactions (Netter et al. 1987). PEN is a wellknown heavy metal chelator and has been therapeutically utilised for heavy metal toxicities since the 1950s (Walshe 1956). PEN has been shown to chelate zinc from spermatozoa (Andrews et al. 1994) and such effects were postulated to improve sperm motility (Wroblewski et al. 2003). PEN is also an excellent chelator of copper and the resulting chelate is highly stable (Aitken et al. 2012). Ram spermatozoa are highly sensitive to copper toxicity and display head-to-head agglutination in the presence of this heavy metal (White 1955). It is possible that copper which is bound to sperm proteins or present in the semen diluents at trace levels is causing sperm agglutination and that the binding of copper by PEN is the mechanism by which this molecule prevents agglutination. This may explain why sheep serum, which contains appreciable levels of copper (average of $14 \mu \mathrm{M}, 7-22$ range) (Laven \& Smith 2008) also provokes an agglutination response.

An alternate explanation for the mechanism of action of PEN is provided by its ability to donate an electron to other molecules and participate as a reductant in redox reactions. PEN, and other thiols (compounds with a sulfhydryl group), have been shown to initiate sperm release through the reduction of sperm surface disulfides to sulfhydryls (Talevi et al. 2007, Gualtieri et al. 2009, 2010). It is probable that PEN may prevent or revert sperm association by the reduction of disulphide bonds of a sperm protein, which are required for sperm binding, to free sulfhydryls.

Agglutination is undesirable in vitro because it makes sperm handling difficult and is not compatible with sperm assays that rely on the analysis of single cells (e.g. CASA, flow cytometry). As agglutination occurs when trying to capacitate ram spermatozoa in TALP, it was important to assess if the inclusion of PEN in this medium would interfere in the capacitation process. It would seem unlikely as low doses of PEN $(20 \mu \mathrm{M})$, in conjunction with hypotaurine and epinephrine (PHE), have been included in multiple bovine IVF protocols to improve oocyte penetration and embryo quality (Miller et al. 1994, Goncalves et al. 2014, Kang et al. 2015).
PEN has also been used in protein-free media to promote capacitation (Andrews \& Bavister 1989, Keskintepe \& Brackett 1996). Its mode of action was thought to mimic albumin depletion of zinc from the acrosome region of the sperm head, which has been associated with capacitation (Andrews et al. 1994). Other studies found that PEN had no effect on fertilisation capacity in TALP medium supplemented with or without capacitation stimulating substances (e.g. heparin, caffeine, serum) (Pavlok 2000, Pavlok et al. 2001). Our findings are in agreement with these latter studies as PEN had no global effect on tyrosine phosphorylation under any of the assayed conditions with the exception of one 220-kDa band in the TALP $3 \mathrm{~h}+$ CAP STIM treatment which showed a greater volume intensity in the presence of PEN compared to its absence (Fig. 6). This strongly indicates that PEN does not inhibit tyrosine phosphorylation of sperm proteins under capacitating conditions and suggests PEN can be supplemented to capacitating media. As tyrosine phosphorylation of high molecular weight proteins $(56+\mathrm{kDa})$ only occurred in the presence of CAMP elevating agents (CAMP, PDE inhibitors) it is recommended that these are also included in ram sperm capacitating media (Fig. 6, Supplementary Table 1).

The inclusion of PEN in the ram sperm capacitation medium allowed a wider array of functional assays to be performed that analyse single cells (e.g. CASA and flow cytometry). Flow cytometric analysis of membrane lipid disorder (M540) showed similar results to the western blot data. Namely, that capacitation associated lipid membrane disorder of viable spermatozoa required the presence of cAMP elevating agents (Fig. 7a). At $3 \mathrm{~h}$, the CAP-STIM capacitation protocol also displayed adequate levels of viable and acrosome intact spermatozoa $(50.8 \pm 5.7 \%$; Fig. $7 \mathrm{~b})$ and motile spermatozoa (70.6土 3.5; Table 2) indicating that this protocol was optimal for the in vitro capacitation and assessment of ram spermatozoa. Taken together, these results suggest that $1 \mathrm{mM}$ PEN can be added to existing ram sperm capacitation protocols (TALP $+1 \mathrm{mM}$ db-cAMP, caffeine and theophylline) to achieve a sperm population which displays high levels of tyrosine phosphorylated proteins (Fig. 5), a high percentage of fluid plasma membranes (Fig. 7) while remaining motile (Table 2), viable (Fig. 7), acrosome-intact (Fig. 7) and non-agglutinated.

In summary, the dilution of ram spermatozoa in TALP can result in autologous sperm binding in a highly specific and persistent manner. Agglutination can be ameliorated by the thiol, penicillamine, possibly through the reduction or chelation of agents involved in the agglutination process (e.g. copper). Penicillamine does not affect protein tyrosine phosphorylation under capacitating conditions and can be included in capacitation protocols to allow the in vitro assessment of ram sperm capacitation. 


\section{Supplementary data}

This is linked to the online version of the paper at http://dx.doi. org/10.1530/REP-15-0413.

\section{Declaration of interest}

The authors declare that there is no conflict of interest that could be perceived as prejudicing the impartiality of the research reported.

\section{Funding}

This work was supported by funding from the NSW Stud Merino Breeders Association Trust and Australian Wool Innovation Limited.

\section{Acknowledgements}

The authors are grateful for the technical assistance of K Heasman.

\section{References}

Aalseth EP, Senger PL \& Becker WC 1978 The relationship of sperm viability and concentration to serum-induced head-to-head agglutination of bovine spermatozoa. Journal of Reproduction \& Fertility 53 193-196. (doi:10.1530/jrf.0.0530193)

Aitken RJ, Harkiss D, Knox W, Paterson M \& Irvine DS 1998 A novel signal transduction cascade in capacitating human spermatozoa characterised by a redox-regulated, cAMP-mediated induction of tyrosine phosphorylation. Journal of Cell Science 111 645-656.

Aitken RJ, Gibb Z, Mitchell LA, Lambourne SR, Connaughton HS \& De Iuliis GN 2012 Sperm motility is lost in vitro as a consequence of mitochondrial free radical production and the generation of electrophilic aldehydes but can be significantly rescued by the presence of nucleophilic thiols. Biology of Reproduction 87 110. (doi:10.1095/ biolreprod.112.102020)

Andrews JC \& Bavister BD 1989 Capacitation of hamster spermatozoa with the divalent cation chelators D-penicillamine, L-histidine, and L-cysteine in a protein-free culture medium. Gamete Research 23 159-170. (doi:10.1002/mrd.1120230203)

Andrews JC, Nolan JP, Hammerstedt RH \& Bavister BD 1994 Role of zinc during hamster sperm capacitation. Biology of Reproduction 51 1238-1247. (doi:10.1095/biolreprod51.6.1238)

Boatman DE \& Bavister BD 1984 Stimulation of rhesus monkey sperm capacitation by cyclic nucleotide mediators. Journal of Reproduction \& Fertility 71 357-366. (doi:10.1530/jrf.0.0710357)

Bromfield EG, Aitken RJ, Gibb Z, Lambourne SR \& Nixon B 2014 Capacitation in the presence of methyl- $\beta$-cyclodextrin results in enhanced zona pellucida-binding ability of stallion spermatozoa. Reproduction 147 153-166. (doi:10.1530/REP-13-0393)

Brown DV \& Senger PL 1982 Influence of incubation in utero on motility and head-to-head agglutination of ejaculated rabbit spermatozoa. Journal of Reproduction \& Fertility 66 283-289. (doi:10.1530/jrf.0. 0660283)

Casao A, Mendoza N, Pérez-Pé R, Grasa P, Abecia JA, Forcada F, CebriánPérez JA \& Muino-Blanco T 2010 Melatonin prevents capacitation and apoptotic-like changes of ram spermatozoa and increases fertility rate. Journal of Pineal Research 48 39-46. (doi:10.1111/j.1600-079X.2009. 00722.x)

Chang MC 1984 The meaning of sperm capacitation a historical perspective. Journal of Andrology 5 45-50. (doi:10.1002/j.1939-4640. 1984.tb00775.x)

Colas C, James P, Howes L, Jones R, Cebrian-Perez JA \& MuinoBlanco T 2008 Cyclic-AMP initiates protein tyrosine phosphorylation independent of cholesterol efflux during ram sperm capacitation. Reproduction Fertility and Development 20 649-658. (doi:10.1071/ RD08023)

Colas C, Cebrian-Perez JA \& Muino-Blanco T 2010 Caffeine induces ram sperm hyperactivation independent of CAMP-dependent protein kinase. International Journal of Andrology 33 E187-E197. (doi:10.1111/j.13652605.2009.00991.x)

Correia J, Michelangeli F \& Publicover S 2015 Regulation and roles of $\mathrm{Ca}^{2+}$ stores in human sperm. Reproduction 150 R65-R76. (doi:10.1530/REP15-0102)

Coy P, Canovas S, Mondejar I, Saavedra MD, Romar R, Grullon L, Matas C \& Aviles M 2008 Oviduct-specific glycoprotein and heparin modulate sperm-zona pellucida interaction during fertilization and contribute to the control of polyspermy. PNAS 105 15809-15814. (doi:10.1073/pnas. 0804422105)

Ehrenwald E, Foote RH \& Parks JE 1990 Bovine oviductal fluid components and their potential role in sperm cholesterol efflux. Molecular Reproduction and Development 25 195-204. (doi:10.1002/mrd.1080250213)

Flesch FM, Brouwers JF, Nievelstein PF, Verkleij AJ, van Golde LM, Colenbrander B \& Gadella BM 2001 Bicarbonate stimulated phospholipid scrambling induces cholesterol redistribution and enables cholesterol depletion in the sperm plasma membrane. Journal of Cell Science $1143543-3555$.

Funahashi H \& Day BN 1993 Effects of follicular fluid at fertilization in vitro on sperm penetration in pig oocytes. Journal of Reproduction \& Fertility 99 97-103. (doi:10.1530/jrf.0.0990097)

Goncalves FS, Barretto LS, Arruda RP, Perri SH \& Mingoti GZ 2014 Heparin and penicillamine-hypotaurine-epinephrine (PHE) solution during bovine in vitro fertilization procedures impair the quality of spermatozoa but improve normal oocyte fecundation and early embryonic development. In Vitro Cellular \& Developmental Biology. Animal 50 39-47. (doi:10.1007/s11626-013-9675-4)

Gordon I 2003 Laboratory Production of Cattle Embryos, In: Biotechnology in agriculture series, 2nd Edition, CAB International, Wallingford, UK: (doi:10.1079/9780851996660.0000)

Gualtieri R, Mollo V, Duma G \& Talevi R 2009 Redox control of surface protein sulphhydryls in bovine spermatozoa reversibly modulates sperm adhesion to the oviductal epithelium and capacitation. Reproduction 138 33-43. (doi:10.1530/REP-08-0514)

Gualtieri R, Mollo V, Barbato V \& Talevi R 2010 Ability of sulfated glycoconjugates and disulfide-reductants to release bovine epididymal sperm bound to the oviductal epithelium in vitro. Theriogenology $\mathbf{7 3}$ 1037-1043. (doi:10.1016/j.theriogenology.2009.11.030)

Harayama H \& Kato S 2002 Relationship between bicarbonate and cyclic nucleotide in the promoting effects on head-to-head agglutination in boar spermatozoa. Asian Journal of Andrology 4 87-96.

Harayama H, Miyake M, Shidara O, Iwamoto E \& Kato S 1998 Effects of calcium and bicarbonate on head-to-head agglutination in ejaculated boar spermatozoa. Reproduction Fertility and Development 10 445-450. (doi:10.1071/RD98124)

Harrison RAP \& Gadella BM 2005 Bicarbonate-induced membrane processing in sperm capacitation. Theriogenology 63 342-351. (doi:10.1016/j.theriogenology.2004.09.016)

Huneau D, Crozet N \& Ahmed-Ali M 1994 Estrous sheep serum as a potent agent for ovine IVF: effect on cholesterol efflux from spermatozoa and the acrosome reaction. Theriogenology 42 1017-1028. (doi:10.1016/0093691X(94)90123-Z)

Jin M, Fujiwara E, Kakiuchi Y, Okabe M, Satouh Y, Baba S, Chiba K \& Hirohashi N 2011 From the Cover: most fertilizing mouse spermatozoa begin their acrosome reaction before contact with the zona pellucida during in vitro fertilization. PNAS 108 4892-4896. (doi:10.1073/pnas. 1018202108)

Kang SS, Koyama K, Huang W, Yang Y, Yanagawa Y, Takahashi Y \& Nagano M 2015 Addition of D-penicillamine, hypotaurine, and epinephrine (PHE) mixture to IVF medium maintains motility and longevity of bovine sperm and enhances stable production of blastocysts in vitro. Journal of Reproduction and Development 61 99-105. (doi:10.1262/jrd.2014-112)

Kay V \& Robertson L 1998 Hyperactivated motility of human spermatozoa: a review of physiological function and application in assisted reproduction. Human Reproduction Update 4 776-786. (doi:10.1093/ humupd/4.6.776) 
Keskintepe L \& Brackett BG 1996 In vitro developmental competence of in vitro-matured bovine oocytes fertilized and cultured in completely defined media. Biology of Reproduction 55 333-339. (doi:10.1095/ biolreprod55.2.333)

Killian G 2011 Evidence that oviduct secretions influence sperm function: a retrospective view for livestock. Journal of Animal Science 89 1315-1322. (doi:10.2527/jas.2010-3349)

Laven R \& Smith S 2008 Copper deficiency in sheep: an assessment of the relationship between concentrations of copper in serum and plasma. New Zealand Veterinary Journal 56 334-338. (doi:10.1080/00480169. 2008.36856)

Leahy T \& Gadella BM 2011 Sperm surface changes and physiological consequences induced by sperm handling and storage. Reproduction 142 759-778. (doi:10.1530/REP-11-0310)

Leahy T \& Gadella BM 2015 New insights into the regulation of cholesterol efflux from the sperm membrane. Asian Journal of Andrology 17 561-567. (doi:10.4103/1008-682X.153309)

Lefebvre R \& Suarez SS 1996 Effect of capacitation on bull sperm binding to homologous oviductal epithelium. Biology of Reproduction 54 575-582. (doi:10.1095/biolreprod54.3.575)

Li F, Pi WH, Zhu HZ, Zhang SS, Liu SR \& Xue JL 2006 The effect of estrous ewe serum and heparin on in vitro fertilization and subsequent embryonic development in sheep. Small Ruminant Research 63 226-232. (doi:10.1016/j.smallrumres.2005.02.019)

Lindahl PE \& Sjöblom P 1981 On mechanisms of head-to-head association in bovine spermatozoa. Biology of Reproduction 25 29-43. (doi:10. 1095/biolreprod25.1.29)

Mann T 1964 The Biochemistry of Semen and of the Male Reproductive Tract, 2nd Edition; London: Methuen and Co. Ltd.

Marquez B \& Suarez SS 2004 Different signaling pathways in bovine sperm regulate capacitation and hyperactivation. Biology of Reproduction 70 1626-1633. (doi:10.1095/biolreprod.103.026476)

Miller GF, Gliedt DW, Rakes JM \& Rorie RW 1994 Addition of penicillamine, hypotaurine and epinephrine (PHE) or bovine oviductal epithelial cells (BOEC) alone or in combination to bovine in vitro fertilization medium increases the subsequent embryo cleavage rate. Theriogenology 41 689-696. (doi:10.1016/0093-691X(94)90178-L)

Morton KM, Graaf SP, Campbell A, Tomkins LM, Maxwell WM \& Evans G 2005 a Repeat ovum pick-up and in vitro embryo production from adult ewes with and without FSH treatment. Reproduction in Domestic Animals 40 422-428. (doi:10.1111/j.1439-0531.2005.00603.x)

Morton KM, Catt SL, Hollinshead FK, Maxwell WM \& Evans G 2005b The effect of gamete co-incubation time during in vitro fertilization with frozen-thawed unsorted and sex-sorted ram spermatozoa on the development of in vitro matured adult and prepubertal ewe oocytes. Theriogenology 64 363-377. (doi:10.1016/j.theriogenology.2004.12.004)

Mukherjee AB \& Cohen MM 1970 Development of normal mice by in vitro fertilization. Nature 228 472-473. (doi:10.1038/228472a0)

Netter P, Bannwarth B, Pere P \& Nicolas A 1987 Clinical pharmacokinetics of D-penicillamine. Clinical Pharmacokinetics 13 317-333. (doi:10. 2165/00003088-198713050-00003)

Parrish JJ, Suskoparrish J, Winer MA \& First NL 1988 Capacitation of bovine spermatozoa by heparin. Biology of Reproduction 38 1171-1180. (doi:10.1095/biolreprod38.5.1171)
Parrish JJ, Suskoparrish JL, Handrow RR, Sims MM \& First NL 1989 Capacitation of bovine spermatozoa by oviduct fluid. Biology of Reproduction 40 1020-1025. (doi:10.1095/biolreprod40.5.1020)

Pavlok A 2000 D-penicillamine and granulosa cells can effectively extend the fertile life span of bovine frozen-thawed spermatozoa in vitro: effect on fertilization and polyspermy. Theriogenology 53 1135-1146. (doi:10.1016/S0093-691X(00)00258-2)

Pavlok A, Kubelka M \& Peknicova J 2001 The effect of various capacitation active compounds and capacitation time on the in vitro fertility and protein tyrosine phosphorylation profiles of bovine sperm. Zygote 9 25-38. (doi:10.1017/S0967199401001046)

Senger PL \& Saacke RG 1976 Serum-induced head-to-head agglutination of bovine spermatozoa. Journal of Reproduction \& Fertility 47 215-219. (doi:10.1530/jrf.0.0470215)

Senger PL, McCutchan JF \& Hillers JK 1981 Influence of blood-serum from bulls and heifers on head-to-head agglutination and acrosomal maintenance in bovine spermatozoa. Biology of Reproduction 25 433-437. (doi:10.1095/biolreprod25.2.433)

Talevi R, Zagami M, Castaldo M \& Gualtieri R 2007 Redox regulation of sperm surface thiols modulates adhesion to the fallopian tube epithelium. Biology of Reproduction 76 728-735. (doi:10.1095/ biolreprod.106.056028)

Tervit HR, Whittingham DG \& Rowson LEA 1972 Successful culture in vitro of sheep and cattle ova. Journal of Reproduction \& Fertility 30 493-497. (doi:10.1530/jrf.0.0300493)

Visconti PE, Galantino-Homer H, Moore GD, Bailey JL, Ning XP, Fornes M \& Kopf GS 1998 The molecular basis of sperm capacitation. Journal of Andrology 19 242-248. (doi:10.1002/j.1939-4640.1998.tb01994.x)

Walshe JM 1956 Penicillamine, a new oral therapy for Wilson's disease. American Journal of Medicine 21 487-495. (doi:10.1016/00029343(56)90066-3)

White IG 1955 The toxicity of heavy metals to mammalian spermatozoa. Australian Journal of Experimental Biology and Medical Science 33 359-366. (doi:10.1038/icb.1955.36)

Whittingham DG 1968 Fertilization of mouse eggs in vitro. Nature 220 592-593. (doi:10.1038/220592a0)

Wroblewski N, Schill WB \& Henkel R 2003 Metal chelators change the human sperm motility pattern. Fertility and Sterility $\mathbf{7 9}$ 1584-1589. (doi:10.1016/S0015-0282(03)00255-3)

Yanagimachi R 2011 Mammalian sperm acrosome reaction: where does it begin before fertilization? Biology of Reproduction 85 4-5. (doi:10.1095/ biolreprod.111.092601)

Yang DH, McMillan AG, Standley NT, Shannon P \& Xu ZZ 2012 Extracellular calcium is involved in egg yolk-induced head-to-head agglutination of bull sperm. Theriogenology 78 1476-1486. (doi:10. 1016/j.theriogenology.2012.06.021)

Received 3 September 2015

First decision 30 September 2015

Revised manuscript received 17 November 2015

Accepted 23 November 2015 